\title{
YouTube Videos and Informed Decision-Making About COVID-19 Vaccination: Successive Sampling Study
}

Charles E Basch ${ }^{1}$, PhD; Corey H Basch², EdD, MPH; Grace C Hillyer ${ }^{3}$, EdD, MPH; Zoe C Meleo-Erwin ${ }^{2}$, PhD, MA; Emily A Zagnit ${ }^{4}$, MS, MPH

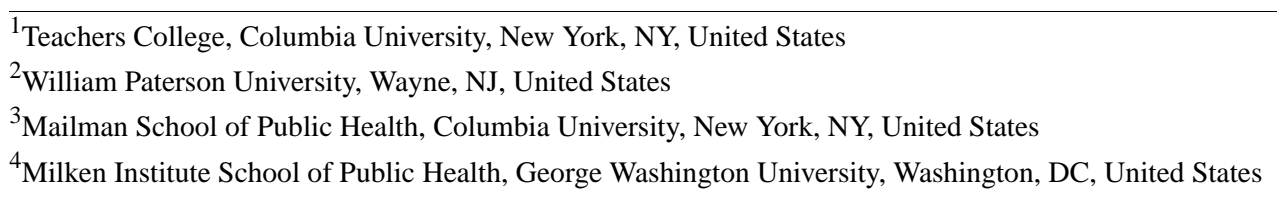

Corresponding Author:

Charles E Basch, PhD

Teachers College, Columbia University

$525 \mathrm{~W} 120$ th St

New York, NY, 10027

United States

Phone: 12126783983

Email: ceb35@ columbia.edu

\section{Abstract}

Background: Social media platforms such as YouTube are used by many people to seek and share health-related information that may influence their decision-making about COVID-19 vaccination.

Objective: The purpose of this study was to improve the understanding about the sources and content of widely viewed YouTube videos on COVID-19 vaccination.

Methods: Using the keywords "coronavirus vaccination," we searched for relevant YouTube videos, sorted them by view count, and selected two successive samples (with replacement) of the 100 most widely viewed videos in July and December 2020, respectively. Content related to COVID-19 vaccines were coded by two observers, and inter-rater reliability was demonstrated.

Results: The videos observed in this study were viewed over 55 million times cumulatively. The number of videos that addressed fear increased from 6 in July to 20 in December 2020, and the cumulative views correspondingly increased from $2.6 \%(1,449,915$ views) to $16.6 \%(9,553,368$ views). There was also a large increase in the number of videos and cumulative views with respect to concerns about vaccine effectiveness, from 6 videos with approximately 6 million views in July to 25 videos with over 12 million views in December 2020. The number of videos and total cumulative views covering adverse reactions almost tripled, from 11 videos with approximately 6.5 million (11.7\% of cumulative views) in July to 31 videos with almost 15.7 million views (27.2\% of cumulative views) in December 2020.

Conclusions: Our data show the potentially inaccurate and negative influence social media can have on population-wide vaccine uptake, which should be urgently addressed by agencies of the United States Public Health Service as well as its global counterparts.

(JMIR Public Health Surveill 2021;7(5):e28352) doi: 10.2196/28352

\section{KEYWORDS}

YouTube; vaccination; COVID-19; social media; communication; misinformation; disinformation; adverse reactions

\section{Introduction}

At the end of 2019, the World Health Organization (WHO) was informed by the Chinese health authorities about a cluster of pneumonia cases, which was shortly thereafter attributed to a novel coronavirus (SARS-CoV-2) [1]. By the end of January 2020, the WHO characterized these outbreaks as a public health emergency [2]. At the time of writing this manuscript, approximately 1 year following this declaration, over 2 million deaths worldwide [3] had been directly attributed to COVID-19, the disease caused by SARS-CoV-2. At a similar time, the United States' Centers for Disease Control and Prevention (CDC) issued a warning that a variant of SARS-CoV-2, first identified in England in late 2020 and known as "B.1.1.7," had been detected in at least 10 US states [4]. Research suggests 
that B.1.1.7, as with other identified variants circulating globally, is more highly transmissible. The spread of the variant is of great public health concern in terms of repercussions on case counts and, consequently, hospital capacity and eventual mortality [4]. To say that the impacts of the COVID-19 global pandemic on morbidity, mortality, and global economies have been devastating would be a vast understatement. The degree to which the pandemic has exacerbated preexisting economic and health inequities has been staggering. Yet, the record speed with which multiple COVID-19 vaccinations were developed and received emergency use authorization in under a year's time not only provides hope but represents an astounding scientific accomplishment.

In early January 2020, scientists first made the genome sequence of SARS-CoV-2 available on the web [5], and by mid-March 2020, Moderna's experimental messenger RNA (mRNA)-based vaccine entered phase 1 of clinical trials [6]. By early December 2020, regulators in the United Kingdom approved the emergency authorization status for the Pfizer and BioNTech COVID-19 vaccines [7], and 6 days later, the United States Food and Drug Administration (FDA) followed suit [8]. By December 18, 2020, a second mRNA vaccine developed by Moderna was also granted emergency use authorization in the United States by the FDA [9]. Although the rollout of vaccines in many countries has been slower than anticipated [10], as of March 1, 2021, nearly 7.8 billion vaccinations have been administered globally [11]. It is well known that the pipeline from vaccine development to distribution is normally rather slow, in no small part due to the tremendous expense involved. However, the rapid sequencing of the virus (SARS-CoV-2), international scientific collaboration, and government financial support [6] have helped to dramatically speed up the pace in this case. The nature of the mRNA vaccines, which do not require culturing or fermentation but instead rely on synthetic RNA, has further facilitated more rapid development [6].

Despite the highly encouraging safety and efficacy profiles of COVID-19 vaccines that have been granted emergency use authorization, thus far, the very processes that allowed for rapid development have also been a source of public concern, with possible negative effects on the uptake of vaccination [12]. Vaccine hesitancy is multi-factorial phenomenon, often driven by a confluence of factors. Not the least of which is a mistrust of scientific experts and government officials [13], which, for some populations, is grounded in the trauma of racist exploitation, disregard, and injustice [14]. Although vaccine hesitancy has a long history $[15,16]$, it is fair to say that today, the internet facilitates, if not drives, both vaccine misinformation and disinformation [17]. Vaccine misinformation pertains to erroneous conclusions based on incomplete or incorrect facts, whereas vaccine disinformation involves the purposeful spread of falsehoods related to both specific vaccines and vaccination, in general [17]. The spread of misinformation is likely facilitated by fear and misunderstanding of vaccine development and approval processes. In contrast, in the latter case, the intent is clearly nefarious in nature.

Social media platforms have become a dominant communication channel through which people seek and share health-related information $[18,19]$. Research suggests that this is no less the case for information on COVID-19 [20]. Although different age cohorts tend to prefer different social media platforms, overall, YouTube is extremely popular, with nearly three-quarters of the US adult population known to have used the platform [21]. Founded in 2005, YouTube has over 2 billion users [22]. YouTube videos can be accessed in 80 different languages, and over a billion hours of video are streamed every day [22]. As with social media platforms in general, health-related content shared on YouTube is often not empirically grounded and yet can easily be accessed [23]. Research on coronavirus-related videos on YouTube is nascent but the results thus far are mixed, with some studies finding that the majority of video content is reliable [24,25], whereas other studies, including those previously undertaken by authors of this study group [26], demonstrating otherwise. At the time of this study, there is little published research on COVID-19 vaccination content on YouTube, with the exception of our previous study that revealed that the majority of videos were uploaded by news outlets and did not contain misinformation [27]. Our prior investigation was conducted relatively early in the pandemic (early-April 2020). Continued monitoring and analysis of social media coverage of COVID-19 vaccine messages is vital to improve its understanding among public health officials about responding to questions and concerns that may produce vaccine hesitance and impede community mitigation. The purpose of this study was, therefore, to build on and update the findings of our previous investigation and add to the repository of scientific knowledge on COVID-19 social media content.

\section{Methods}

Using a cleared browsing history, and the keywords "coronavirus vaccination," we searched YouTube for relevant videos, sorted them by view count, and conducted a successive sampling study. Two successive samples (with replacement) were selected and each included the 100 most widely viewed videos in July and December 2020, respectively. Half of the videos in each sample were independently coded by one researcher (EZ or $\mathrm{CHB}$ ), and a 10\% random sample was coded by both researchers to demonstrate inter-rater reliability (using the Kappa coefficient), which was found to be high ( $\kappa=.969$ in Round 1 and $\kappa=.963$ in Round 2). Metadata were gathered for each video, including date uploaded, source, length (in minutes), and number of views. A video content checklist developed for this and our prior study of vaccine use on YouTube was based on a CDC fact sheet [27]. Content coverage related to vaccine development, fast-tracking, emergency use authorization, manufacturing, dissemination, eligibility, dosing, herd immunity, concerns about adverse reactions, fear, effectiveness, and immunity duration were dichotomously coded as "present" or "absent." The analysis comprised frequency and percentage distributions for dichotomous content variables and the proportion of total cumulative views garnered by videos addressing each content category. For continuous variables (number of video views and length of video), mean and SD were computed. Analysis was conducted within each of the successive samples using SPSS software (version 25.0; IBM Corp.). At William Paterson University and Columbia 
University, studies that do not involve human subjects are not subject to review; the Institutional Review Board at Teachers College of Columbia University reviewed the study protocol and deemed the research exempt from review.

\section{Results}

The videos evaluated in this study were viewed over 55 million times. Twenty-nine of the videos from the July sample were retained in December. The mean length of the videos in the two samples was 7.5 minutes (see Table 1). Over $80 \%$ of the widely viewed videos in each sample originated from television or internet news, whereas fewer than $10 \%$ of the videos originated from consumers, professionals, or entertainment television. Between the two rounds, there were 14 professional videos, 7 in each round with 4 overlapping between the rounds. The professional videos in Round 1 comprised $4.4 \%$ of the total views $(2,403,245 / 55,086,261)$ and those in Round 2 comprised $3.8 \%$ of the total views $(2,157,142 / 57,506,506)$.

The vaccine development process was the most covered topic, followed by fast-tracking of the vaccine (see Table 2). The vaccine manufacturing process was covered in 31 videos in July 2020 and 36 videos in December 2020, garnering almost one-third of the cumulative views in each sample. There was a $44 \%$ increase in the share of cumulative views of videos addressing vaccine dissemination from July $(10,197,203 / 55,086,261,18.5 \%)$ to December 2020 $(14,732,085 / 57,506,506,25.6 \%)$. This is attributable to the approximately $60 \%$ increase in videos covering this topic, from 17 in July 2020 to 27 in December 2020. From July to December, videos covering vaccine eligibility more than doubled (from 12 to 25), with the cumulative views increasing from <5.5 million to >9.5 million; however, even in December 2020 , videos covering this topic accounted for only $16.8 \%$ $(9,652,883 / 57,506,506)$ of the cumulative views. The number of videos addressing vaccine dosing increased from 4 to 26 , and cumulative views of videos addressing dosing increased from $4 \%(2,217,251$ views) to $15.7 \%(9,017,039$ views $)$. There was relatively little change in the percentage of cumulative views garnered by videos addressing herd immunity or the duration of immunity derived from COVID-19 vaccines.

Table 1. Characteristics of successive samples of YouTube videos about COVID-19 vaccination, July through December 2020.

\begin{tabular}{|c|c|c|}
\hline \multirow[t]{2}{*}{ Characteristic } & \multicolumn{2}{|l|}{ Value, $\mathrm{n}(\%)$} \\
\hline & July $2020(n=100)$ & December $2020(n=100)$ \\
\hline \multicolumn{3}{|l|}{ Video views } \\
\hline Total views & $55,086,261$ & $57,506,506$ \\
\hline Mean views (SD) & $550,863(620,691)$ & $575,065(604,247)$ \\
\hline Range & $135,729-4,016,406$ & $196,294-4,038,435$ \\
\hline \multicolumn{3}{|l|}{ Video length (minutes) } \\
\hline Mean length (SD) & $8.2(9.4)$ & $7.2(6.3)$ \\
\hline Range & $0.4-51.4$ & $0.5-35.4$ \\
\hline \multicolumn{3}{|l|}{ Source } \\
\hline Consumer & $5(5)$ & $8(8)$ \\
\hline Professional & $7(7)$ & $7(7)$ \\
\hline Television or internet news & $84(84)$ & $81(81)$ \\
\hline Entertainment television & $4(4)$ & $4(4)$ \\
\hline
\end{tabular}


Table 2. Content of successive samples of YouTube videos about COVID-19 vaccination, July through December 2020.

\begin{tabular}{|c|c|c|c|c|c|c|}
\hline \multirow[t]{2}{*}{ Content covered } & \multicolumn{3}{|l|}{ July 2020} & \multicolumn{3}{|c|}{ December 2020} \\
\hline & $\begin{array}{l}\text { Number of } \\
\text { videos (n) }\end{array}$ & Number of views (n) & $\begin{array}{l}\text { Percentage of cu- } \\
\text { mulative views (\%) }\end{array}$ & $\begin{array}{l}\text { Number of } \\
\text { videos }(n)\end{array}$ & $\begin{array}{l}\text { Number of views } \\
\text { (n) }\end{array}$ & $\begin{array}{l}\text { Percentage of } \\
\text { cumulative } \\
\text { views }(\%)\end{array}$ \\
\hline Vaccine development & 77 & $47,745,687$ & 86.7 & 93 & $52,907,010$ & 92.0 \\
\hline Fast-tracking & 57 & $31,891,480$ & 57.9 & 70 & $40,140,849$ & 69.8 \\
\hline Emergency use authorization & 3 & 593,609 & 1.1 & 22 & $10,132,084$ & 17.6 \\
\hline Vaccine manufacturing & 31 & $17,498,885$ & 31.8 & 36 & $18,817,111$ & 32.7 \\
\hline Vaccine dissemination & 17 & $10,197,203$ & 18.5 & 27 & $14,732,085$ & 25.6 \\
\hline Vaccine eligibility & 12 & $5,410,203$ & 9.8 & 25 & $9,652,883$ & 16.8 \\
\hline Vaccine dosing & 4 & $2,217,251$ & 4.0 & 26 & $9,017,039$ & 15.7 \\
\hline Herd immunity & 5 & $2,286,901$ & 4.2 & 6 & $3,173,062$ & 5.5 \\
\hline Adverse reactions to the vaccine & 11 & $6,456,465$ & 11.7 & 31 & $15,686,832$ & 27.3 \\
\hline Fear & 6 & $1,449,915$ & 2.6 & 20 & $9,553,368$ & 16.6 \\
\hline Concerns about effectiveness & 6 & $5,966,961$ & 10.8 & 25 & $12,317,526$ & 21.4 \\
\hline Concerns about immunity duration & 5 & $2,415,092$ & 4.4 & 10 & $3,953,045$ & 6.9 \\
\hline
\end{tabular}

In contrast, the number of videos that addressed fear increased from 6 (July 2020) to 20 (December 2020), and the corresponding percentage of cumulative views increased from $2.6 \%(1,449,915$ views) to $16.6 \%(9,553,368$ views). There was also a large increase in the number of videos and cumulative views between the two samples with respect to concerns about vaccine effectiveness, from 6 videos with approximately 6 million views to 25 videos with over 12 million views, and a commensurate increase in the proportion of cumulative views (from $10.8 \%$ to $21.4 \%$ ). The number of videos and total cumulative views covering adverse reactions almost tripled from 11 videos with approximately 6.5 million views $(11.7 \%$ of cumulative views) in July to 31 videos with almost 15.7 million views (27.2\% of cumulative views) in December 2020.

\section{Discussion}

Vaccinations have resulted in the eradication of small pox and considerable reductions in measles, mumps, rubella, polio, varicella, and many other infectious diseases [28]. Studying vaccinations historically shows the large time gaps that occur between scientific conceptualization, development, manufacturing, approval, and population-wide uptake. The current pandemic provides a remarkable example of unprecedented speed in developing, testing, and emergency use authorization of multiple vaccines [6,29,30], and bodes well for primary prevention of COVID-19.

The only two ways to achieve primary prevention of COVID-19 is by decreasing exposure to SARS-CoV-2 and evolving variants and reducing susceptibility through active infection or vaccination (although the efficacy of vaccines is less than $100 \%$ and the duration of immunity conferred through active infection or vaccination is equivocal). As long as COVID-19 is spreading through communities, social distancing, mask use, and hand hygiene are the best ways for reducing exposure among susceptible people [31-33]. Manufacturing and distributing vaccines in ways that result in widespread uptake is the key public health strategy for reducing population-wide susceptibility to COVID-19 [34].

Behaviors for reducing exposure and susceptibility both require voluntary decision-making by individuals. Reducing exposure through social distancing, mask use, avoiding crowded or poorly ventilated spaces, and practicing hand hygiene is challenging for many reasons. Not only are there economic pressures for frontline workers to be around others, but because people are inherently social and have been isolated to a greater or lesser degree since the pandemic was declared a global public health emergency by the WHO in January 2020, it is also inevitable that COVID-19 will continue to be transmitted within and among communities. Hence, reducing susceptibility through vaccination provides the greatest long-term hope for primary prevention of COVID-19.

The main public health challenge now is the population-wide vaccine uptake and concomitant herd immunity. Observations in fields ranging from agriculture to technology indicate that something new-in this case, the uptake of a new vaccine-follows predictable patterns of adoption, with some population segments likely to adopt an innovation, and successive population segments adopting at slower rates over time until the last segment-laggards, who are most resistant and may never adopt the innovation [35]. A substantial proportion of the United States [36] and the global [37] population is reportedly hesitant to receive a COVID-19 vaccination. In the United States, population segments that appear most hesitant vary by demographic and social characteristics; for example, those who appear to be more hesitant are women, younger and middle-aged adults, non-Hispanic Black people, adults with lower income and educational attainment and no health insurance, and adults residing in nonmetropolitan areas [36,38]. Various reasons for vaccine hesitancy have been identified, including concerns about 
side effects, safety, effectiveness, lack of trust in the government, and how politics has influenced vaccine development [35].

The main implication for public health education is that different messages are more or less relevant to assist different population segments to make informed decisions about vaccination, and the nature of messaging is dynamic and influenced by rapidly changing social context. Communication strategies have been proposed based on the level of vaccine hesitancy [39]. The current challenge is different than those of the past, not only because the speed with which new information about COVID-19 and vaccination effectiveness and availability is being generated but also because of the speed with which information is disseminated throughout the population via social media. Although a very small proportion of serious adverse reactions have occurred following the 76+ million doses of COVID-19 vaccinations administered between December 14, 2020, and March 1, 2021 [40], our results show that the number of widely viewed YouTube videos covering the topic of adverse reactions to COVID-19 vaccine almost tripled from 11 in July to 31 in December 2020, with a commensurate increase in the proportion of cumulative views (from $11.7 \%$, representing 6.4 million views, to $27.2 \%$, representing 15.6 million views). The coverage of concerns about effectiveness more than quadrupled with regard to the number of videos (6 videos in July to 25 videos in December 2020), and almost doubled with regard to the proportion of cumulative views (from $10.8 \%$, representing approximately 6 million views, to $21.4 \%$, representing $>12$ million views). The extent to which messages are widely viewed can affect consumers' beliefs and decision-making regarding the uptake of COVID-19 vaccination. Public health agencies responsible for helping people make informed decisions about vaccination must, therefore, monitor widely viewed social media on a daily basis to identify and address sources of misinformation and disinformation. In the context of this global public health emergency, we believe social media companies also share this responsibility [41].

A comprehensive national prevention strategy is needed to mitigate further morbidity and mortality caused by COVID-19, and an essential element of this strategy is to discover ways to assist the public in making informed decisions about vaccination $[42,43]$. Disseminating up-to-date and accurate information through social media is one of the most effective ways to reach a large proportion of the population. To date, public health agencies have had limited effectiveness in achieving this goal. Equally, if not more concerning, is that the efforts by individuals and groups to discourage vaccination are effectively reaching people who are uncertain or ambivalent about being vaccinated
[44]. It is also essential for an effective national prevention strategy to recognize and address other barriers that preclude individuals' ability to make informed decisions about vaccination, such as limited access to the internet necessary to schedule an appointment, loss of income from taking time off from work, and lack of transportation.

This study is delimited in scope in several ways. First, only the time period between July and December 2020 was sampled. The choice of these two points in time was somewhat arbitrary, but represents different pivotal points in the vaccine development process. Second, only 100 videos were included in each sample. Third, only certain content was coded. Fourth, attributes of videos were only examined in relation to the number of views, and we cannot distinguish between the number of views and the number of viewers. We did not have data on the characteristics of viewers such as geography or demographics, nor did we know the extent to which, if any, these videos impacted behavior. Finally, we relied on the keywords "coronavirus vaccine" to search for and sort the videos; thus, we relied on YouTube search algorithms. The main outcome for this study - the number of views - relied on YouTube numbers and sorting algorithms. Despite these delimitations, with the exception of our pilot study [27], we did not identify any published studies examining YouTube videos related to COVID-19 vaccine messages. Although the sample size was small, the videos examined were widely viewed. This study was intended as a stepping-stone to improve understanding about videos that reach a large number of people. This is not only important for reaching the general population with accurate information about vaccinations but also for being aware and responding to disinformation and misinformation that may be disseminated through widely viewed content on social media, and influence the hesitancy of people who are uncertain about receiving a vaccine.

In conclusion, our data show the potentially inaccurate and negative influence social media can have on population-wide vaccine uptake that should be urgently addressed by agencies of the United States Public Health Service as well as its global counterparts. At the time of this study (the second half of 2020), videos uploaded by public health agencies or professionals have had limited presence among the widely viewed YouTube videos that have reached millions of people. Different approaches are needed to understand and address the concerns subgroups of people have about COVID-19 vaccination. Improving the extent to which social media reaches the public with comprehensible, up-to-date, and scientifically accurate information must be a part of a comprehensive national strategy to help people make informed decisions about vaccination.

\section{Conflicts of Interest}

None declared.

\section{References}

1. Neilson S, Woodward A. A comprehensive timeline of the coronavirus pandemic at 1 year, from China's first case to the present. Insider. 2020 Dec 24. URL: https://www.businessinsider.com/ coronavirus-pandemic-timeline-history-major-events-2020-3 [accessed 2020-03-01] 
2. Statement on the second meeting of the International Health Regulations (2005) Emergency Committee regarding the outbreak of novel coronavirus (2019-nCoV). World Health Organization. 2020 Jan 30. URL: https://tinyurl.com/26txmcpr [accessed 2021-03-01]

3. Ahluwalia S. Global COVID-19 death toll tops 2 million. Thomson Reuters. 2021 Jan 15. URL: https://www.reuters.com/ article/us-health-coronavirus-global-casualties/global-covid-19-death-toll-tops-2-million-idUSKBN29K2EW [accessed 2021-03-01]

4. Galloway SE, Paul P, MacCannell DR, Johansson MA, Brooks JT, MacNeil A, et al. Emergence of SARS-CoV-2 B.1.1.7 lineage - United States, December 29, 2020-January 12, 2021. MMWR Morb Mortal Wkly Rep 2021 Jan 22;70(3):95-99 [FREE Full text] [doi: $\underline{10.15585 / \mathrm{mmwr} . \mathrm{mm} 7003 \mathrm{e} 2]}$ [Medline: $\underline{33476315]}$

5. Paden CR, Tao Y, Queen K, Zhang J, Li Y, Uehara A, et al. Rapid, sensitive, full-genome sequencing of Severe Acute Respiratory Syndrome Coronavirus 2. Emerg Infect Dis 2020 Oct;26(10):2401-2405 [FREE Full text] [doi:

10.3201/eid2610.201800] [Medline: $\underline{32610037]}$

6. Lurie N, Saville M, Hatchett R, Halton J. Developing Covid-19 vaccines at pandemic speed. N Engl J Med 2020 May 21;382(21):1969-1973. [doi: 10.1056/nejmp2005630]

7. Ledford H, Cyranoski D, Van Noorden R. The UK has approved a COVID vaccine - here's what scientists now want to know. Nature 2020 Dec;588(7837):205-206. [doi: 10.1038/d41586-020-03441-8] [Medline: 33288887]

8. FDA Takes Key Action in Fight Against COVID-19 By Issuing Emergency Use Authorization for First COVID-19 Vaccine. U.S. Food \& Drug Administration. 2020 Dec 11. URL: https://www.fda.gov/news-events/press-announcements/ fda-takes-key-action-fight-against-covid-19-issuing-emergency-use-authorization-first-covid-19\#: :text=Today\%2C\%20the $\% 20 \mathrm{U}$. S.\%20Food\%20and,years\%20of\%20age\%20and\%20older [accessed 2021-03-01]

9. Moderna COVID-19 vaccine. U.S. Food \& Drug Administration. URL: https://www.fda.gov/ emergency-preparedness-and-response/coronavirus-disease-2019-covid-19/moderna-covid-19-vaccine [accessed 2021-03-01]

10. Beaumont P. Covid vaccinations: slow start around world brings dose of reality. The Guardian. 2021 Jan 5. URL: https:/ /www.theguardian.com/world/2021/jan/05/covid-vaccinations-slow-start-around-world-dose-reality [accessed 2021-03-01]

11. Ritchie H, Ortiz-Ospina E, Beltekian D, Mathieu E, Hasell J, Macdonald B. Coronavirus (COVID-19) vaccinations. Our World in Data. URL: https://ourworldindata.org/covid-vaccinations [accessed 2021-03-01]

12. Kekatos M. Nearly $80 \%$ of Americans think that the speedy approval process of a coronavirus vaccine is driven by politics-NOT by proof that shots work. The Harris Poll. URL: https://theharrispoll.com/ nearly-80-of-americans-think-that-the-speedy-approval-process-of-a-coronavirus-vaccine-is-driven-by-politics-not-by-proof-that-shots-work/ [accessed 2021-03-01]

13. Verger P, Dubé E. Restoring confidence in vaccines in the COVID-19 era. Expert Rev Vaccines 2020 Nov;19(11):991-993. [doi: 10.1080/14760584.2020.1825945] [Medline: 32940574]

14. Warren RC, Forrow L, Hodge DA, Truog RD. Trustworthiness before Trust - Covid-19 Vaccine Trials and the Black Community. N Engl J Med 2020 Nov 26;383(22):e121. [doi: 10.1056/nejmp2030033]

15. Harrison EA, Wu JW. Vaccine confidence in the time of COVID-19. Eur J Epidemiol 2020 Apr;35(4):325-330 [RREE Full text] [doi: 10.1007/s10654-020-00634-3] [Medline: 32318915]

16. McAteer J, Yildirim I, Chahroudi A. The VACCINES Act: Deciphering vaccine hesitancy in the time of COVID-19. Clin Infect Dis 2020 Jul 28;71(15):703-705 [FREE Full text] [doi: 10.1093/cid/ciaa433] [Medline: 32282038]

17. Igoe K. Establishing the truth: Vaccines, social media, and the spread of misinformation. Harvard T.H. Chan School of Public Health. 2019 Jul 10. URL: https://www.hsph.harvard.edu/ecpe/vaccines-social-media-spread-misinformation/ [accessed 2021-03-01]

18. Fox S. The social life of health information. Pew Research Center. 2014 Jan 15. URL: https://www.pewresearch.org/ fact-tank/2014/01/15/the-social-life-of-health-information/ [accessed 2021-03-01]

19. The Internet and Health. Pew Research Center. 2013 Feb 12. URL: https://www.pewresearch.org/internet/2013/02/12/ the-internet-and-health/, [accessed 2021-03-01]

20. Larson HJ. A call to arms: helping family, friends and communities navigate the COVID-19 infodemic. Nat Rev Immunol 2020 Aug;20(8):449-450 [FREE Full text] [doi: 10.1038/s41577-020-0380-8] [Medline: $\underline{32616908]}$

21. Perrin A, Anderson M. Share of U.S. adults using social media, including Facebook, is mostly unchanged since 2018. Pew Research Center. 2019 Apr 10. URL: https://www.pewresearch.org/fact-tank/2019/04/10/ share-of-u-s-adults-using-social-media-including-facebook-is-mostly-unchanged-since-2018/ [accessed 2021-03-01]

22. YouTube for Press. URL: https://www.youtube.com/about/press/ [accessed 2021-03-01]

23. Madathil KC, Rivera-Rodriguez AJ, Greenstein JS, Gramopadhye AK. Healthcare information on YouTube: A systematic review. Health Informatics J 2015 Sep;21(3):173-194 [FREE Full text] [doi: 10.1177/1460458213512220] [Medline: 24670899]

24. D'Souza RS, D'Souza S, Strand N, Anderson A, Vogt MNP, Olatoye O. YouTube as a source of medical information on the novel coronavirus 2019 disease (COVID-19) pandemic. Glob Public Health 2020 Jul;15(7):935-942. [doi: 10.1080/17441692.2020.1761426] [Medline: $\underline{32397870]}$ 
25. Marchal N, Au H, Howard P. Coronavirus News and Information on YouTube: A Content Analysis of Popular Search Terms. COMPROP Data Memo 2020. 2020 Apr 17. URL: https://comprop.oii.ox.ac.uk/wp-content/uploads/sites/93/2020/ 04/YouTube-Memo-COVID-19-FINAL.pdf [accessed 2021-03-01]

26. Basch C, Hillyer G, Meleo-Erwin Z, Jaime C, Mohlman J, Basch C. Preventive behaviors conveyed on YouTube to mitigate transmission of COVID-19: Cross-sectional study. JMIR Public Health Surveill 2020 Apr 2;6(2):e18807. [doi: 10.2196/18807]

27. Basch CH, Hillyer GC, Zagnit EA, Basch CE. YouTube coverage of COVID-19 vaccine development: implications for awareness and uptake. Hum Vaccin Immunother 2020 Nov 01;16(11):2582-2585. [doi: 10.1080/21645515.2020.1790280] [Medline: 32701403]

28. Greenwood B. The contribution of vaccination to global health: past, present and future. Philos Trans R Soc Lond B Biol Sci 2014;369(1645):20130433 [FREE Full text] [doi: 10.1098/rstb.2013.0433] [Medline: 24821919]

29. Bloom DE, Cadarette D, Ferranna M, Hyer RN, Tortorice DL. How new models of vaccine development For COVID-19 have helped address an epic public health crisis. Health Aff (Millwood) 2021 Mar;40(3):410-418. [doi: 10.1377/hlthaff.2020.02012] [Medline: 33539191]

30. Mukherjee S, Barouch D, Hamburg M, Weiss S, Yancopoulos G. Can a vaccine for Covid-19 be developed in record time? The New York Times Magazine. 2020 Jun 9. URL: https://www.nytimes.com/interactive/2020/06/09/magazine/covid-vaccine. html [accessed 2021-03-01]

31. Social Distancing - Keep a Safe Distance to Slow the Spread. Centers for Disease Control and Prevention. 2020. URL: https://www.cdc.gov/coronavirus/2019-ncov/prevent-getting-sick/social-distancing.html [accessed 2021-03-01]

32. Science Brief: Community Use of Cloth Masks to Control the Spread of SARS-CoV-2. Centers for Disease Control and Prevention. 2020 Nov. URL: https://www.cdc.gov/coronavirus/2019-ncov/more/masking-science-sars-cov2. html\#: :text=SARS\%2DCoV\%2D2\%20infection\%20is,of\%20SARS\%2DCoV\%2D2 [accessed 2021-03-01]

33. Handwashing: Clean Hands Save Lives. Centers for Disease Control and Prevention. URL: https://www.cdc.gov/handwashing/ index.html [accessed 2021-03-01]

34. Slaoui M, Hepburn M. Developing safe and effective Covid vaccines - Operation Warp Speed's strategy and approach. N Engl J Med 2020 Oct 29;383(18):1701-1703. [doi: 10.1056/nejmp2027405]

35. McKee C, Bohannon K. Exploring the reasons behind parental refusal of vaccines. J Pediatr Pharmacol Ther 2016;21(2):104-109 [FREE Full text] [doi: 10.5863/1551-6776-21.2.104] [Medline: 27199617]

36. Nguyen KH, Srivastav A, Razzaghi H, Williams W, Lindley MC, Jorgensen C, et al. COVID-19 vaccination intent, perceptions, and reasons for not vaccinating among groups prioritized for early vaccination - United States, September and December 2020. MMWR Morb Mortal Wkly Rep 2021 Mar 12;70(6):217-222 [FREE Full text] [doi: 10.15585/mmwr.mm7006e3] [Medline: 33571174 ]

37. Lin C, Tu P, Beitsch LM. Confidence and receptivity for COVID-19 vaccines: A rapid systematic review. Vaccines (Basel) 2020 Dec 30;9(1):16 [FREE Full text] [doi: 10.3390/vaccines9010016] [Medline: 33396832]

38. Hamel L, Kirzinger A, Munana C, Brodie M. KFF COVID-19 Vaccine Monitor: December 202. KFF (Kaiser Family Foundation). 2020 Dec 15. URL: https://www.kff.org/coronavirus-covid-19/report/

kff-covid-19-vaccine-monitor-december-2020/ [accessed 2021-03-01]

39. Wood S, Schulman K. Beyond politics - Promoting Covid-19 vaccination in the United States. N Engl J Med 2021 Feb 18;384(7):e23. [doi: 10.1056/nejmms2033790]

40. Selected adverse events reported after COVID-19 vaccination. Centers for Disease Control and Prevention. URL: https:/ /www.cdc.gov/coronavirus/2019-ncov/vaccines/safety/adverse-events.html [accessed 2021-03-01]

41. Donovan J. Social-media companies must flatten the curve of misinformation. Nature 2020 Apr 14. [doi: 10.1038/d41586-020-01107-z] [Medline: 32291410]

42. Lee TH, Chen AH. Last-mile logistics of Covid vaccination - The role of health care organizations. N Engl J Med 2021 Feb 25;384(8):685-687. [doi: 10.1056/nejmp2100574]

43. Volpp KG, Loewenstein G, Buttenheim AM. Behaviorally informed strategies for a national COVID-19 vaccine promotion program. JAMA 2021 Jan 12;325(2):125-126. [doi: 10.1001/jama.2020.24036] [Medline: 33315079]

44. Johnson NF, Velásquez N, Restrepo NJ, Leahy R, Gabriel N, El Oud S, et al. The online competition between pro- and anti-vaccination views. Nature 2020 Jun;582(7811):230-233. [doi: 10.1038/s41586-020-2281-1] [Medline: $\underline{32499650]}$

\author{
Abbreviations \\ CDC: Centers for Disease Control and Prevention \\ FDA: Food and Drug Administration \\ mRNA: messenger RNA \\ WHO: World Health Organization
}


Edited by T Sanchez; submitted 02.03.21; peer-reviewed by G Wilmink, J Lee, N Noreen; comments to author 09.04.21; revised version received 16.04.21; accepted 19.04.21; published 06.05.21

Please cite as:

Basch CE, Basch CH, Hillyer GC, Meleo-Erwin ZC, Zagnit EA

YouTube Videos and Informed Decision-Making About COVID-19 Vaccination: Successive Sampling Study

JMIR Public Health Surveill 2021;7(5):e28352

URL: https://publichealth.jmir.org/2021/5/e28352

doi: $10.2196 / 28352$

PMID: 33886487

CCharles E Basch, Corey H Basch, Grace C Hillyer, Zoe C Meleo-Erwin, Emily A Zagnit. Originally published in JMIR Public Health and Surveillance (https://publichealth.jmir.org), 06.05.2021. This is an open-access article distributed under the terms of the Creative Commons Attribution License (https://creativecommons.org/licenses/by/4.0/), which permits unrestricted use, distribution, and reproduction in any medium, provided the original work, first published in JMIR Public Health and Surveillance, is properly cited. The complete bibliographic information, a link to the original publication on https://publichealth.jmir.org, as well as this copyright and license information must be included. 